\title{
An analysis of the role of collagenase and protease in the enzymatic dissociation of the rat pancreas for islet isolation
}

\author{
G.H.J. Wolters, G.H. Vos-Scheperkeuter, J.H. M.van Deijnen and R.van Schilfgaarde \\ Department of Surgery, University of Groningen, Groningen, The Netherlands
}

\begin{abstract}
Summary. Crude Clostridium histolyticum collagenase is widely used for the enzymatic degradation of pancreatic extracellular matrix in order to isolate the islets of Langerhans. The variable enzymatic composition of crude collagenases is a critical issue which contributes to the poor reproducibility of islet isolation procedures. In this study, the separate contributions of collagenase and protease to the islet isolation process were analysed by testing various combinations of purified collagenase and purified protease in rat pancreas dissociations under conditions which eliminated all other proteolytic activity. Under these conditions, complete tissue dissociation by purified collagenase required $99 \pm 10 \mathrm{~min}$, whereas increasing amounts of protease progressively reduced this time to a minimum of $36 \pm 1 \mathrm{~min}$. Histochemical analysis of the dissociation process showed that protease enhanced the degradation of all four major components of the extracellular matrix: collagen was degraded more completely, while proteoglycans, glycoproteins
\end{abstract}

and elastin were degraded at a higher rate. Pancreas dissociation under the present, strictly controlled conditions resulted in a high yield of viable islets: $4.2-5.0 \mu$ islet tissue volume $(3,300-3,800$ islets) were isolated per $\mathrm{g}$ pancreas in the presence of a high or low protease concentration, respectively. Prolonged dissociation in the presence of protease resulted in a dramatic decrease in islet yield which correlated with the observation that the enzyme accelerated islet disintegration. It is concluded that the collagenase-induced dissociation of the extracellular matrix is facilitated by protease. Our study shows that high yields of viable islets can be obtained under controlled enzymatic conditions, provided that the exposure of islets to protease is limited.

Key words: Collagenase, protease, pancreas, extracellular matrix, islet isolation.
A large variety of procedures for the isolation of islets of Langerhans from the pancreas has been described during the past decades. The insight obtained into the numerous factors influencing the isolation process [1-3] has eventually allowed for successful islet transplantations in large mammals [4-6]. The fact that clinical success has only been observed for grafts derived from multiple donors [710] indicates that the overall efficacy of islet isolation is still low. In addition, the process is poorly controlled as indicated by its low reproducibility [11].

In an adult rat pancreas the total number of islets is $3,300-6,000[12,13]$ and the total islet volume is about $8.5 \mu 1$ [14]. Under optimal conditions, about 1,400 islets equivalent to $4.4 \mu \mathrm{l}$ of islet volume have been recovered $[3,14]$ either by ductal collagenase administration or by the chopped tissue collagenase digestion technique [14]. However, usual islet recoveries range between 400 and 1200 islets per pancreas, suggesting that islet isolation procedures can be further improved.
Isolation of islets requires a selective dissociation of the pancreas. This implies that the extracellular matrix (ECM), a complex network of collagen, proteoglycans including glycosaminoglycans, glycoproteins and elastin [15], should be degraded without affecting the structural and functional integrity of the islets. The usual approach applies digestion of the tissue with commercial Clostridium histolyticum collagenase, which is a mixture of six collagenases with distinct substrate specificities $[16,17]$ and various other enzymes such as aminopeptidase [18], clostripain [19], phospholipase C [3] and neutral protease [20]. The composition of C. histolyticum collagenase is an important source of variability in islet isolation $[2,3]$. The major contaminant is neutral protease, referred to as protease in this study, which has been reported to contribute positively to the digestion of pancreatic tissue [21]. We have therefore analysed the precise role of protease when supplemented to collagenase. This was done by dissociating the pancreas with purified collagenase and varying 
amounts of purified protease, while eliminating all endogenous proteolytic enzymes. Under these controlled enzymatic conditions, the degradation of the major ECM components was studied with histochemical methods, and the yield, the morphological quality and the viability of the isolated islets were assessed.

\section{Materials and methods}

\section{Materials}

Crude C. histolyticum collagenase (lot no. 10439320-68, containing 0.44 Wünsch U collagenase/mg and $125 \mathrm{U}$ protease measured as caseinase/mg; Boehringer Mannheim, Mannheim, FRG) was used as a source for the isolation of protease. Purified $C$. histolyticum collagenase (Sigma Chemical Co., St. Louis Mo., USA; type VII, lot nos. 19F-6828 and 40H-6822) contained 1790 and 2000 Mandl $U$ collagenase/mg, respectively, and negligible amounts of clostripain $(0.04$ and $<0.07 \mathrm{U} / \mathrm{mg}$ ), non-specific protease $(<0.01$ and $0.06 \mathrm{U} / \mathrm{mg})$ and tryptic activity $(0.02 \mathrm{U} / \mathrm{mg}$ and not detectable). Gel analysis confirmed the high degree of purity of Sigma type VII collagenase (data not shown). One Wünsch unit corresponds to about $1800 \mathrm{Mandl}$ units but this conversion factor is not consistent (product information, Boehringer)

Sephacryl S-200 HR was from Pharmacia Fine Chemicals (Uppsala, Sweden); bovine serum albumin (BSA) was from Boehringer; high molecular weight markers for gel electrophoresis, alcian blue $8 \mathrm{GX}$, orcein and trypsin inhibitors from turkey egg white and soybean were from Sigma; sirius red F3BA and fast green FCF were from Chroma (Stuttgart-Untertürkheim, FRG); nuclear fast red, azocarmine $\mathrm{G}$, aniline blue, aldehyde fuchsin, Coomassie brilliant blue R250, casein according to Hammarsten, and Entellan were from Merck (Darmstadt, FRG); orange G was from BDH Chemicals Ltd. (Poole, UK); Krebs-Ringer-HEPES (KRH) pH 7.4 was, expressed as mmol/l, composed of $118.58 \mathrm{NaCl}, 4.69 \mathrm{KCl}$, $2.52 \mathrm{CaCl}_{2}, 1.18 \mathrm{KH}_{2} \mathrm{PO}_{4}, 1.18 \mathrm{MgSO}_{4}$, and $25 \mathrm{HEPES}$ and gassed with oxygen.

\section{Histochemical staining procedures}

Collagen was stained with sirius red-fast green at $\mathrm{pH} 2[22,23]$. All other staining procedures were derived from Romeis [24]. Proteoglycans (including glycosaminoglycans) were stained with alcian blue $8 \mathrm{GX}$ at $\mathrm{pH} 2.5$ and counterstained with nuclear fast red, glycoproteins were stained with the periodic-acid-Schiff (PAS) method and counterstained with Mayer's haemalum, and elastin was stained with orcein. Morphological quality of pancreatic islets was assessed after staining with aldehyde fuchsin-azan (AF-azan). Stained sections were dehydrated through graded ethanol, cleared in xylene and mounted in Entellan.

The staining intensities of individual ECM components were graded on a scale of $0-4$ using light microscopy by three persons without knowledge of the origin of the slide. The staining intensity in native tissue was denoted 4 , whereas the complete absence of stain was denoted 0 . Likewise, the morphological quality of islets was graded on a scale of $0-4,0$ indicating complete dissociation of all the islets. Intact islets with a smooth periphery with no lines of fracture and a normal AF-azan staining were graded 4 . A slightly damaged islet periphery was graded 3 , and when about half of the islets were damaged and the cell border lines were hazy, islet integrity was graded 2 . When nearly all islets were damaged or fragmented, integrity was graded 1.

\section{Pancreatic tissue dissociation and islet isolation}

Male Wistar rats $(350 \mathrm{~g})$ were anaesthetized using diethylether and bled by cardiotomy. The pancreata $(949 \pm 30 \mathrm{mg})$ were removed, divided into quarters and sub-divided into four fragments. The
16 tissue fragments obtained were distributed evenly over the incu bation vessels and the contents of each vessel were adjusted to a total of $300 \mathrm{mg}$ tissue. After chopping, the tissue was washed three times with KRH containing $10 \%$ (weight/volume, w/v) BSA.

For histochemical analysis of the dissociation, pancreatic tissue was transferred to a $25 \mathrm{ml}$ Erlenmeyer flask containing $10 \mathrm{ml} \mathrm{KRH}$ (gassed with oxygen) containing (a) collagenase type VII and protease, and (b) $10 \%$ BSA and trypsin inhibitors ( $2 \mathrm{mg} / \mathrm{ml}$ turkey egg white inhibitor and $3 \mathrm{mg} / \mathrm{ml}$ soybean inhibitor) in order to suppress the release and activity of proteolytic enzymes from pancreatic tissue and to ensure an optimal islet yield [3]. Per $300 \mathrm{mg}$ tissue $7,620 \mathrm{U}$ purified collagenase and 0,100 or $800 \mathrm{U}$ purified protease were added. The second combination $(7,620 \mathrm{U}$ collagenase $+100 \mathrm{U}$ protease) was chosen because Sigma type XI collagenase, which is frequently used for islet isolation, contains similar activities of these enzymes. The flasks were gassed with oxygen and incubated in an incubator at $37^{\circ} \mathrm{C}$ with 200 cycles per min with an amplitude of $2 \mathrm{~cm}$. At time zero and every $15 \mathrm{~min}$ thereafter, a tissue sample of $0.9 \mathrm{ml}$ was taken, chilled to $0^{\circ} \mathrm{C}$, washed with $\mathrm{KRH}$ and fixed overnight in Bouin's solution. Subsequently, samples were dehydrated in graded series of ethanol and embedded in paraffin. Sections of $5 \mu \mathrm{m}$ were subjected to the various selective histochemical stainings.

For determination of the dissociation time, pancreatic tissue (300 mg) was incubated in $10 \mathrm{ml} \mathrm{KRH}$ containing BSA, trypsin inhibitors, 7,620 U purified collagenase and $0,100,200,400,800$, or $1,600 \mathrm{U}$ purified protease. The time required for complete dissociation, defined as tissue dissociation to fragments of $0.25 \mathrm{~mm}$ or smaller, was determined by microscopic inspection.

For determination of islet yield and viability, pancreatic tissue (300 mg) was completely dissociated with 7,620 U purified collagenase and 100 or $800 \mathrm{U}$ purified protease, as described above. The reaction was stopped with ice cold KRH-10\% BSA followed by three washings. When the effect of prolonged dissociation times on islet yield was tested, a sample of $3 \mathrm{ml}$ was taken at standard dissociation time and incubation was continued during an additional period of $25 \%$ or $50 \%$ of that time. For quantification, all islets were handpicked after washing with $\mathrm{KRH}$ and staining with $0.2 \mathrm{mmol} / \mathrm{l}$ dithizone $[25]$ and the diameters of the islets were measured using a stereomicroscope. The total islet tissue volume isolated from $1 \mathrm{~g}$ pancreatic tissue was calculated from the diameters and number of islets. For in vitro function tests, unstained islets were identified by trans-illumination with a fluorescent lamp [14] and the insulin secretion of four aliquots of ten islets each $(n=6)$ was measured $[14,26]$. Briefly, islets were pre-incubated for $30 \mathrm{~min}$ in $2 \mathrm{ml}$ of Krebs-Ringerbicarbonate containing $0.25 \% \mathrm{BSA}$ and $2.75 \mathrm{mmol} / \mathrm{l}$ glucose. The insulin secreted during three consecutive incubations of $45 \mathrm{~min}$ each at $2.75,16.5$ and $2.75 \mathrm{mmol} / \mathrm{l}$ glucose was measured and expressed in pmol insulin $\cdot \mu \mathrm{g} \mathrm{DNA}{ }^{-1} \cdot 45 \mathrm{~min}^{-1}$.

\section{Purification of protease}

Protease was isolated from crude C. histolyticum collagenase at $4^{\circ} \mathrm{C}$. In small scale purifications, $0.5 \mathrm{~g}$ crude collagenase was dissolved in $50 \mathrm{mmol} / \mathrm{l} \mathrm{Tris}-\mathrm{HCl} \mathrm{pH} 7.5$ containing $5 \mathrm{mmol} / \mathrm{L} \mathrm{CaCl}$ at $50 \mathrm{mg} / \mathrm{ml}$, cleared by filtration over a $0.45 \mu \mathrm{m}$ filter and fractionated on a column $(2.2 \times 145 \mathrm{~cm})$ of Sephacryl S-200 in Tris-CaCl $\mathrm{Cuffer}_{2}[16,27]$. The protease fraction was concentrated by ammonium sulphate precipitation (final saturation $53 \%$ ), dialysed and rechromatographed under identical conditions. For large-scale purifications, protease was first separated from the bulk of collagenase by differential ammonium sulphate precipitation $[28,29]$ and then subjected to chromatography. Crude collagenase $(4 \mathrm{~g}$ ) was dissolved at $20 \mathrm{mg} / \mathrm{ml}$ in Tris- $\mathrm{CaCl}_{2}$ buffer, filtered over a $0.45 \mu \mathrm{m}$ filter and a saturated ammonium sulphate solution was slowly added to achieve a final saturation of $40 \%$. The precipitate formed after $40 \mathrm{~min}$ was collected by centrifugation $(15 \mathrm{~min}$ at $19,000 \times \mathrm{g})$, dissolved in and dialysed against Tris- $\mathrm{CaCl}_{2}$ buffer and chromatographed on the Sephacryl S200 column. The final protease fractions were dialysed against distilled water and freeze-dried. Purification was monitored by measurement of the protease activity and occasionally the collagenolytic activity, and by analysis of the fractions by SDS-PAGE. 


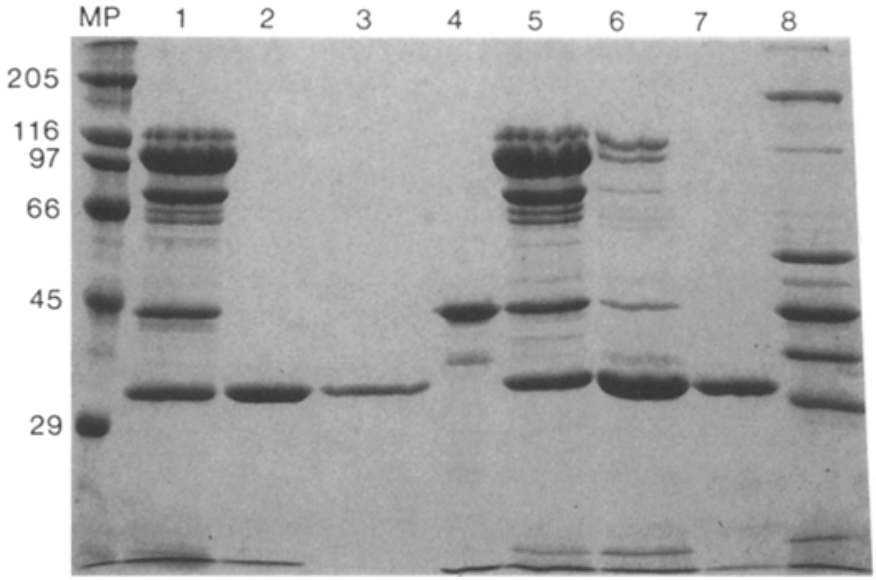

Fig. 1. SDS-PAGE of protease. Lanes 1-3 illustrate the small-scale purification, lanes 5-7 the large-scale purification. Crude $C$. histolyticum collagenase from Boehringer Mannheim is applied in lanes 1 and 5 (about $40 \mu \mathrm{g}$ ); the other lanes contain protease obtained after one cycle of Sephacryl S-200 chromatography (lane 2; $10 \mu \mathrm{g}$ ), after two cycles of Sephacryl S-200 chromatography (lane 3; $3 \mu \mathrm{g}$ ), after ammonium sulphate fractionation (lane $6 ; 20 \mu \mathrm{g}$ ), or after ammonium sulphate fractionation followed by one cycle of Sephacryl S-200 chromatography (lane 7;10 $\mathrm{gg}$ ). MP, Marker proteins (mol. wts. in $\mathrm{kDa}$ indicated on the left), lane 4: $C$. histolyticum clostripain (Sigma), and lane 8: C. perfringens phospholipase C (Sigma)

SDS-PAGE was performed according to Laemmli [30] on minislab gels containing $10 \%(\mathrm{w} / \mathrm{v})$ acrylamide using a Hoefer Mighty Small electrophoresis unit. To prevent proteolysis during incubation of collagenase samples in denaturation buffer (16, and unpublished observations), $10 \mathrm{mmol} / 1$ EDTA was added and samples were boiled immediately. Electrophoresis was completed in $70-90$ min at $15 \mathrm{~mA}$ per gel, and Coomassie blue staining was performed for $1 \mathrm{~h}$ at $60^{\circ} \mathrm{C}$.

\section{Measurement of proteolytic activity}

Proteolytic activity was determined by measuring the hydrolysis of casein [3]. After incubation of $10-40 \mu \mathrm{l}$ sample with $0.5 \mathrm{ml}$ of $1 \%$ (w/v) casein in $100 \mathrm{mmol} / \mathrm{l}$ Tris- $\mathrm{HCl}, 5 \mathrm{mmol} / \mathrm{l} \mathrm{CaCl}$ ( $\mathrm{pH}$ 7.4) during $30 \mathrm{~min}$ at $37^{\circ} \mathrm{C}, 0.7 \mathrm{ml}$ of $13 \%(\mathrm{w} / \mathrm{v})$ trichloroacetic acid was added and samples were centrifuged (10 min at $13,000 \mathrm{rev} / \mathrm{min})$. The absorption of the supernatant was measured at $280 \mathrm{~nm}$ using casein as a standard. One unit of protease is defined as the amount of protease which hydrolyzes $1 \mathrm{mg}$ casein in $30 \mathrm{~min}$. In our assay, 1 unit corresponds to about 2 units caseinase present in Sigma type XI collagenase preparations.

\section{Statistical analysis}

Results are expressed as means \pm SEM. Statistical evaluations were performed with unpaired two-tailed Student's $t$-test.

\section{Results}

\section{Purification of protease}

Fractionation of crude $C$. histolyticum collagenase $(0.5 \mathrm{~g}$, $125 \mathrm{U}$ protease $/ \mathrm{mg}$ solid) on Sephacryl S-200 yielded three peaks. Analysis of enzyme measurements and SDSPAGE showed that collagenase eluted in the second peak, that neutral protease eluted in the last, broad peak and that clostripain could be detected between these two peaks. Similar results have been described by others [16, 27]. Rechromatography of protease on the same column showed a retarded elution profile, suggesting that protease had affinity to the column matrix under these conditions (data not shown). This problem was circumvented in the large-scale purification procedure where chromatography was preceded by ammonium sulphate fractionation. The purified protease $(37.5 \mathrm{mg}$, activity $598 \mathrm{U} / \mathrm{mg}$ solid; mol. wt. $35 \mathrm{kDa}$ ) was shown to be essentially free of collagenase, clostripain or other possible contaminants (Fig. 1, lane 3).

In the large-scale procedure, $4 \mathrm{~g}$ of crude collagenase yielded $77.1 \mathrm{mg}$ of purified protease with an activity of $930 \mathrm{U} / \mathrm{mg}$ solid. SDS-PAGE showed the first step in this procedure, i.e. the ammonium sulphate fractionation, to be a simple and effective tool for removing the bulk of collagenase (Fig. 1, lane 6 vs 5). After chromatography, the protease was found to be electrophoretically homogeneous (Fig. 1, lane 7). A second large-scale purification procedure yielded $63 \mathrm{mg}$ of purified protease with an activity of $1086 \mathrm{U} / \mathrm{mg}$ solid.

\section{Effect of protease concentration on collagenase-induced pancreatic tissue dissociation}

Pancreatic tissue was dissociated with $7,620 \mathrm{U}$ purified collagenase and $0,100,200,400,800$ or $1,600 \mathrm{U}$ purified protease in the presence of BSA and trypsin inhibitors in an oxygen-rich atmosphere. The inhibitors and BSA did not inhibit the collagenase activity as measured by the degradation of native collagen in vitro (data not shown). Measurement of the proteolytic activity in the medium at the start and end of the incubation showed that the added protease was the only source of proteolytic activity present during dissociation (Table 1).

Complete dissociation with collagenase alone required $99 \pm 10$ min (range 71-130 min; Fig. 2). Incidently, a few

Table 1. Level of proteolytic activity during dissociation and viability of the isolated islets

\begin{tabular}{|c|c|c|}
\hline & \multicolumn{2}{|c|}{$\begin{array}{l}\text { Islets isolated with } \\
7,620 \text { units collagenase } \\
\text { combined with }\end{array}$} \\
\hline & $\begin{array}{l}100 \text { units } \\
\text { protease }\end{array}$ & $\begin{array}{l}800 \text { units } \\
\text { protease }\end{array}$ \\
\hline \multicolumn{3}{|c|}{$\begin{array}{l}\text { Proteolytic activity ( } \mathrm{mg} \text { casein } \\
\text { hydrolysed } \cdot 30 \mathrm{~min}^{-1} \text { ) measured } \\
\text { in the dissociation medium at }\end{array}$} \\
\hline $\begin{array}{l}0 \mathrm{~min} \\
32 \mathrm{~min} \\
61 \mathrm{~min}\end{array}$ & $\begin{array}{l}69 \pm 2 \\
- \\
93 \pm 3\end{array}$ & $\begin{array}{l}474 \pm 17 \\
478 \pm 17 \\
-\end{array}$ \\
\hline \multicolumn{3}{|c|}{$\begin{array}{l}\text { Insulin secretion (pmol insulin } \cdot \mu \mathrm{g} \\
\mathrm{DNA}^{-1} \cdot 45 \mathrm{~min}^{-1} \text { ) of the isolated } \\
\text { islets upon incubation in }\end{array}$} \\
\hline $\begin{array}{c}2.75 \mathrm{mmol} / 1 \text { glucose } \\
16.5 \mathrm{mmol} / 1 \text { glucose } \\
2.75 \mathrm{mmol} / 1 \text { glucose }\end{array}$ & $\begin{array}{l}0.79 \pm 0.07 \\
5.22 \pm 0.35 \\
1.32 \pm 0.09\end{array}$ & $\begin{array}{l}0.95 \pm 0.07 \\
7.26 \pm 0.51 \\
1.29 \pm 0.09\end{array}$ \\
\hline
\end{tabular}

Means \pm SEM of six experiments.

a Times correspond to start and end of dissociation procedure 


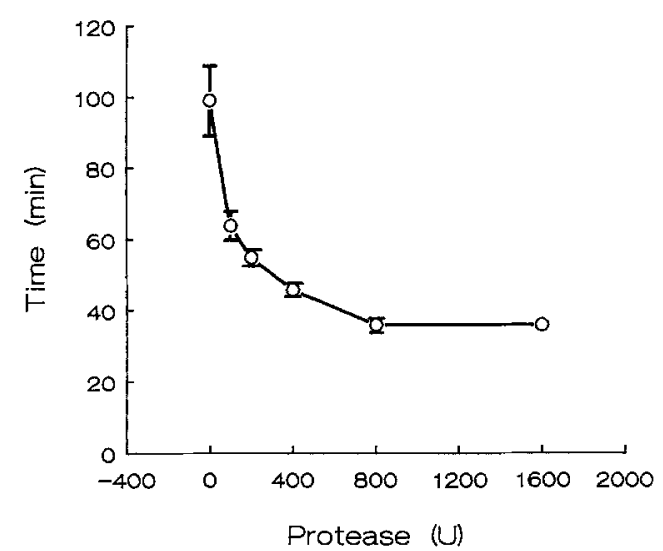

Fig. 2. Effect of protease concentration on dissociation time. Pancreatic tissue $(300 \mathrm{mg})$ was incubated in $10 \mathrm{ml}$ Krebs-Ringer-HEPES containing $10 \%$ bovine serum albumin and trypsin inhibitors, and 7,620 units purified collagenase (Sigma type VII) combined with 0 , $100,200,400,800$ or 1,600 units purified protease. The time required to obtain tissue fragments of $0.25 \mathrm{~mm}$ or smaller (standard dissociation time) was determined for each protease concentration. Values represent means \pm SEM of seven experiments, except for 1,600 units protease $(n=2)$

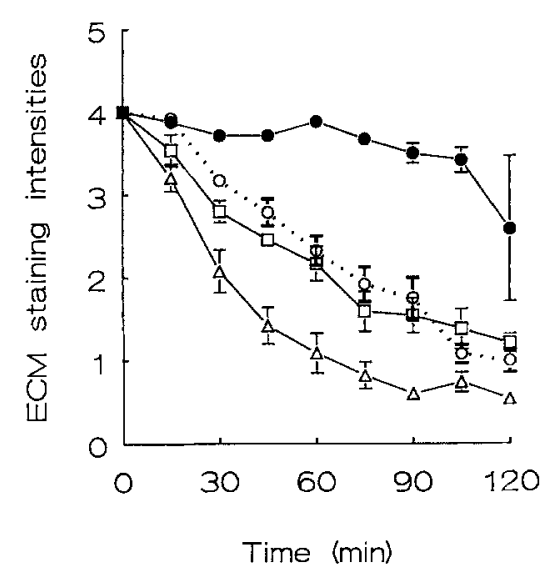

Fig. 3. Degradation of extracellular matrix by purified collagenase. Pancreatic tissue $(300 \mathrm{mg}$ ) was dissociated in $10 \mathrm{ml} \mathrm{Krebs-Ringer-}$ HEPES containing $10 \%$ bovine serum albumin and trypsin inhibitors, and 7,620 U purified collagenase. Histochemical staining was by sirius red (collagen $-\triangle-$ ), periodic acid-Schiff (glycoproteins $-\square-$ ), alcian blue (proteoglycans - $\mathrm{O}_{-}$), and orcein (elastin - - ). Degradation was assessed by scoring staining intensities on a scale of $0-4$, where 4 represents the staining intensity of native tissue and 0 indicates the total absence of staining. Values represent means \pm SEM of four to five experiments. Very small SEMs are not depicted

fragments up to $0.4 \mathrm{~mm}$ were observed at that time which was not the case when protease was present. Addition of a low amount of protease $(100 \mathrm{U} / 10 \mathrm{ml})$ reduced the tissue dissociation to $64 \pm 4 \mathrm{~min}$. Dissociation times decreased further by increasing amounts of protease to a minimum of $36 \pm 1$ min with 800 or $1,600 \mathrm{U} / 10 \mathrm{ml}$ (Fig. 2).

\section{Degradation of various ECM components by collagenase alone}

Collagen (sirius red staining) is seen in the capsule of the native pancreas and in the septa between lobes and lobules. The adventitia of arteries and veins and the periph- ery of ductuli are relatively strongly stained. Sirius red staining is also seen around every acinus whereas islets are partly or completely surrounded by a thin layer. When the tissue is incubated with collagenase alone, the collagen in the tissue decreases after 15 min. Degradation of collagen progresses during $75 \mathrm{~min}$ after which a low residual level of collagen persists up to $120 \mathrm{~min}$ (Fig. 3).

Glycoproteins (PAS-positive staining) are observed as a weak stain in the capsule of native pancreas, and as a thin layer in the septa. Each acinus and all islets are partly or completely surrounded by a thin layer of PAS-positive material. In addition, glycoproteins are seen as a thin layer in the wall of arteries and veins and at the periphery of ducts and nerves. Within the islets glycoproteins are observed in the wall of capillaries. Upon incubation of the tissue with collagenase alone, the PAS staining intensity gradually decreases but does not completely disappear within $120 \mathrm{~min}$ (Fig. 3).

Proteoglycans, as shown by alcian blue (AB) staining, are seen as a weak reaction in the capsule of native pancreas and in the septa between lobes and lobules. ABpositive material is present in the walls of arteries and veins, whereas the periphery of ductuli is relatively strong $\mathrm{AB}$-positive. The acini and the islets are surrounded by a thin layer of AB-positive material, whereas a relatively strong $A B$ staining is seen within the islets, especially near the capillaries. During the collagenase-induced ECM degradation, the amount of proteoglycan gradually decreases between 15 and $120 \mathrm{~min}$ but does not completely disappear (Fig. 3). The time course of the degradation of proteoglycans by purified collagenase is similar to that of glycoproteins and is delayed when compared to collagen degradation (Fig.3). After 60 min of dissociation, the fraction of undigested collagen is significantly lower than that of glycoproteins $(p<0.02)$ and proteoglycans $(p<0.005)$.

Elastin (orcein staining) in native tissue is seen in the walls of arteries, in the adventitia of veins and at the periphery of ductuli. Sporadically, elastin fibers are seen in the septa. Incubation of the tissue with collagenase alone does not result in a detectable decrease of elastin during the first $105 \mathrm{~min}$. Only after $120 \mathrm{~min}$ of digestion there may be some degradation of elastin under these conditions (Fig. 3).

\section{Degradation of various ECM components by collagenase-protease mixtures}

The time course of collagen degradation during incubation of pancreatic tissue with either collagenase alone or collagenase combined with low amounts of protease (i. e. $100 \mathrm{U}$ per $300 \mathrm{mg}$ tissue in $10 \mathrm{ml}$ ) is similar during the first $60 \mathrm{~min}$ (Fig. 4A). Continued degradation of collagen until sirius red staining is absent requires the presence of protease (at $105 \mathrm{~min}, p<0.005$ with both protease concentrations). The initial rate of collagen degradation is higher with $800 \mathrm{U}$ than with $100 \mathrm{U}$ protease $(p<0.02)$. All sirius red staining material disappears from pancreatic tissue within $105 \mathrm{~min}$ when 100 or $800 \mathrm{U}$ of protease are used (Fig. 4A). Careful comparison of islet and exocrine tissue reveals no difference in the degradation of collagens. 

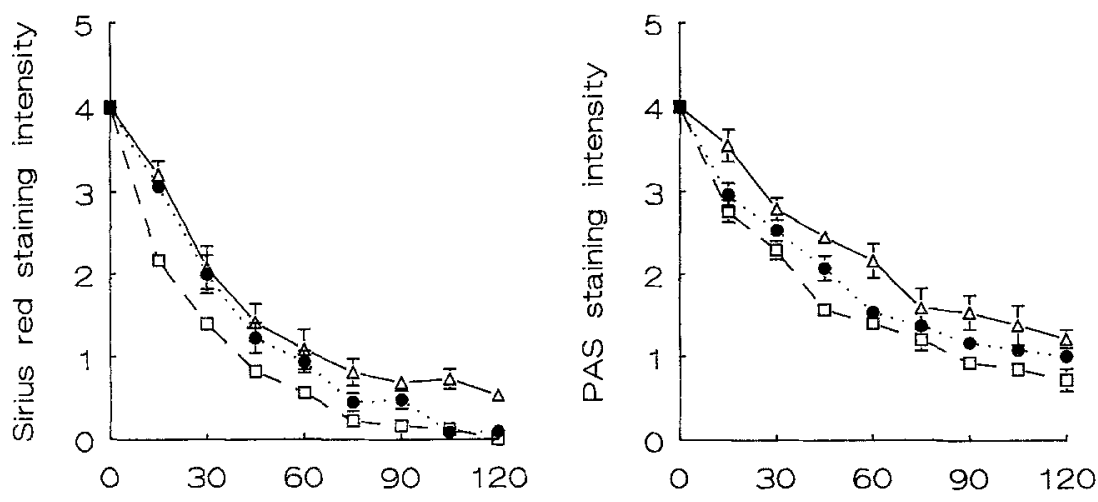

A

Time (min)

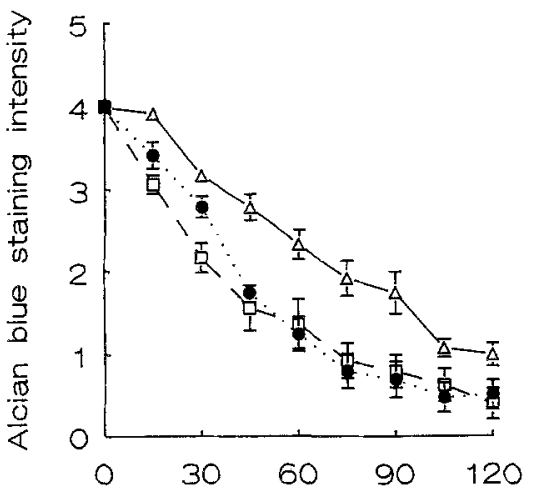

C

Time $(\mathrm{min})$
B

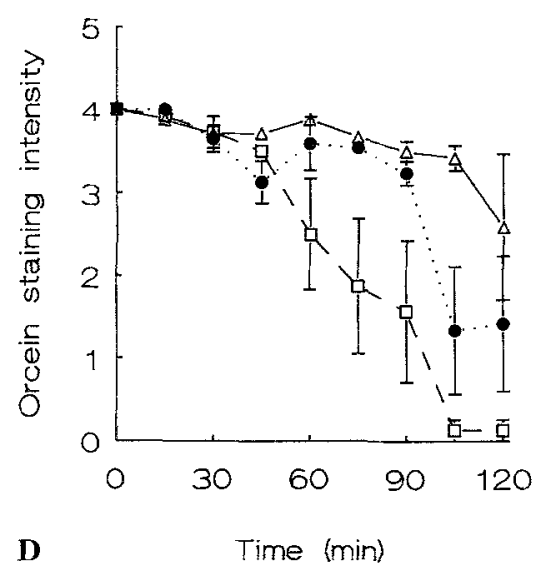

Fig.4A-D. Degradation of collagen (A), glycoproteins $(\mathbf{B})$, proteoglycans including glycosaminoglycans (C), and elastin (D) by various collagenase-protease combinations. Pancreatic tissue $(300 \mathrm{mg}$ ) was dissociated in $10 \mathrm{ml}$ Krebs-RingerHEPES containing $10 \%$ bovine serum albumin and trypsin inhibitors, and 7,620 units purified collagenase combined with either $0\left(-\Delta_{-}^{-}\right), 100(--)$ or $800(-\square-)$ units purified protease. Samples were processed for staining with sirius red (A), periodic-acid-Schiff $(\mathbf{B})$, alcian blue $(\mathbf{C})$ or orcein (D) and staining intensities were scored on a scale of $0-4$. Values represent means \pm SEM of four to five experiments. Very small SEMs are not depicted
Degradation of glycoproteins, visualized by PAS staining, by collagenase alone predominantly occurs between 0 and $75 \mathrm{~min}$ of incubation, after which a residual level of glycoproteins persists (Fig. 4B). The rate of glycoprotein degradation is slightly increased when $100 \mathrm{U}$ protease is added, and somewhat more when $800 \mathrm{U}$ protease are added (at $60 \mathrm{~min}, p<0.025$ and $p<0.02$, respectively). Even after 120 min of enzymatic digestion with $800 \mathrm{U}$ protease, some PAS positive material persists (Fig. 4B). Careful comparison of islet and exocrine tissue reveales no difference in glycoprotein degradation.

Proteoglycans and glycosaminoglycans were visualized in tissue samples in various stages of dissociation by $\mathrm{AB}$ staining. When collagenase alone was used, a gradual decrease in the $A B$ staining intensity is observed starting at $15 \mathrm{~min}$ and continuing up to $120 \mathrm{~min}$ of digestion (Fig. 4C). Complete degradation of the proteoglycans by collagenase alone is not observed within the specified incubation period. Addition of protease results in a more rapid degradation of the proteoglycans (at $60 \mathrm{~min}$, $p<0.01$ and $p<0.05$ with 100 and 800 U protease, respectively). Little difference is observed between the effects of 100 and $800 \mathrm{U}$ protease (Fig. 4C). At $120 \mathrm{~min}$ of dissociation in the presence of protease, a very low level of ABpositive material persists. No difference in the degradation of proteoglycans within islets or in the exocrine tissue is observed.

The disappearance of elastin (orcein staining) from pancreatic tissue by incubation with collagenase is considerably enhanced by the addition of protease (Fig.4D).
When 100 U protease are added, orcein staining decreases after 90 min of digestion. A dramatic difference is observed between digestion of elastin by collagenase alone and that by collagenase supplemented with $800 \mathrm{U}$ protease: after $105 \mathrm{~min}$ of digestion, no degradation is observed by collagenase alone, whereas the presence of high amounts of protease results in a complete removal of elastin (Fig. 4D; $p<0.001$ ). In our view, the disappearance of elastin fibres results from the digestion of vessels and ductuli rather than reflecting the actual degradation of elastin.

\section{Effect of collagenase and protease on islet morphology}

The effect of various collagenase-protease combinations on the structural integrity of the islets was assessed by AFazan staining. When pancreatic tissue is incubated with collagenase alone under completely protease-free conditions, the islets remain undamaged until about $60 \mathrm{~min}$. Thereafter islets become progressively more damaged, and at $120 \mathrm{~min}$ the majority of the islets are damaged (Fig. 5). When the tissue is digested by collagenase supplemented with $100 \mathrm{U}$ protease, the integrity of the islets is maintained until about $15 \mathrm{~min}$, after which the morphological quality of the islets deteriorates. The islet damage observed after $60 \mathrm{~min}$ of dissociation is significantly higher in the presence than in the absence of protease ( $p<0.05$ and $p<0.001$ with 100 and $800 \mathrm{U}$ protease, respectively), while no significant difference between 100 and 800 U protease was observed $(p>0.05)$. At $105 \mathrm{~min}$ of 


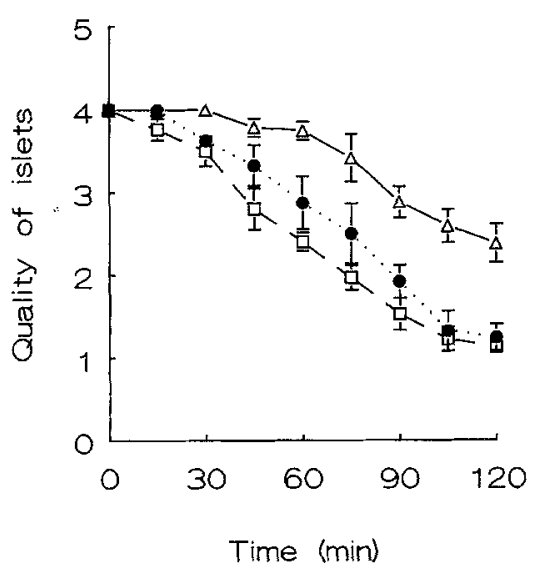

Fig.5. Effect of various collagenase-protease combinations on the morphological quality of islets. Pancreatic tissue $(300 \mathrm{mg})$ was dissociated in $10 \mathrm{ml}$ Krebs-Ringer-HEPES containing $10 \%$ bovine serum albumin and trypsin inhibitors, and 7,620 units purified collagenase combined with $0\left(-\Delta_{-}\right), 100(--)$ or $800\left(-\square_{-}\right)$units purified protease. Samples were processed for staining with aldehyde fuchsin-azan. The degree of islet damage occurring during dissociation was assessed on a scale of 0-4 (0 severe damage, 4 undamaged). Values represent means $\pm S E M$ of four to five experiments. Very small SEMs are not depicted

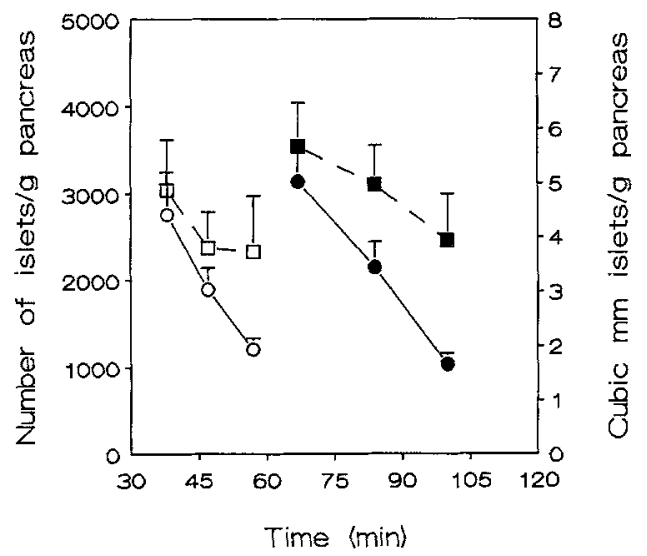

Fig. 6. Effect of prolonged dissociation with various protease concentrations on islet yield. Pancreatic tissue $(300 \mathrm{mg}$ ) was dissociated in $10 \mathrm{ml} \mathrm{Krebs-Ringer-HEPES}$ containing $10 \%$ bovine serum albumin and trypsin inhibitors, and 7,620 units purified collagenase combined with $100\left(-\mathbf{-}-,-\mathbf{-}_{-}\right)$or $800\left(-\square-,-O_{-}\right)$units purified protease. Dissociation with 800 units protease was stopped after $38 \pm 1 \mathrm{~min}$ (i.e. the standard dissociation time, (SDT)), after $47 \pm 2 \min (+25 \%$ SDT $)$ or after $57 \pm 2 \mathrm{~min}(+50 \%$ SDT $)$. Dissociation with 100 units protease was stopped after $66 \pm 2 \mathrm{~min}$ (i.e. the SDT), after $83 \pm 3 \mathrm{~min}(+25 \% \mathrm{SDT})$ or after $99 \pm 3 \mathrm{~min}(+50 \%$ SDT). Islet were hand-picked and quantified, both as number of islets per gramme pancreas $(-\square-,,-\mathbf{-}-)$ and as islet volume per gramme pancreas $\left(-\mathrm{O}_{-},--\right)$. Values represent means $\pm \mathrm{SEM}$ of five experiments in duplicate

dissociation only severely damaged islets are observed (Fig.5).

\section{Effect of protease concentration on islet yield}

Pancreatic tissue was dissociated with collagenase combined with 100 or $800 \mathrm{U}$ protease under conditions which suppressed the endogenous proteolytic activity, and the islet yield was determined. Dissociation was completed in $66 \pm 2$ min with $100 \mathrm{U}$ protease added and in $38 \pm 1 \mathrm{~min}$ with $800 \mathrm{U}$ protease added. At these times, $3 \mathrm{ml}$ samples were taken from the Erlenmeyer flasks and islets were collected by hand-picking. The yield was $4.2 \pm 0.6 \mu \mathrm{l}$ islet tissue volume (or 3,289 \pm 456 islets) per g pancreas with $800 \mathrm{U}$ protease, and $5.0 \pm 0.4 \mu \mathrm{l}$ islet tissue volume (or $3,789 \pm 456$ islets) per g pancreas with $100 \mathrm{U}$ protease (Fig. 6). When $100 \mathrm{U}$ protease was used, all islets were intact, whereas with $800 \mathrm{U}$ protease fragmentation of islets was observed occasionally. The islets, however, were not completely free of exocrine cells. When islets were purified by dextran density gradient centrifugation [26] instead of hand-picking, $79.1 \pm 5.1 \%$ and $85.2 \pm 3.5 \%$ (mean $\pm \mathrm{SEM}, n=6$ ) of the islet tissue was separated from the exocrine tissue after isolation with $100 \mathrm{U}$ and $800 \mathrm{U}$ protease, respectively.

To assess the effect of prolonged dissociation on islet yield, the remainder of the tissue suspension was incubated further and additional samples were taken at times corresponding to $125 \%$ and $150 \%$ of the standard dissociation time. Islet yield decreased considerably: at $150 \%$ standard dissociation time the islet tissue volume isolated from $1 \mathrm{~g}$ pancreas had decreased from 4.2 to $1.9 \pm 0.1 \mu \mathrm{l}$ (3,289 to $2,467 \pm 467$ islets) with 800 U protease, and from 5.0 to $1.8 \pm 0.2 \mu \mathrm{l}(3,789$ to $2,567 \pm 389$ islets $)$ with $100 \mathrm{U}$ protease (Fig. 6). From these data it can be calculated that the rate with which the number of islets decreased during prolonged dissociation with a high amount of protease was not significantly different from that with a low amount of protease $(1.22 \pm 0.25 \%$ and $1.45 \pm 0.29 \%$ per min, respectively; $p>0.05$ ), while a significant decrease in the islet tissue volume was observed $(1.92 \pm 0.13 \%$ and $2.72 \pm 0.26 \%$ per min with 100 and $800 \mathrm{U}$ protease, respectively; $p<0.025$ ). Prolonged dissociation, as compared to standard dissociation, with $100 \mathrm{U}$ protease did not result in completely clean islets, and fragmentation of islets was observed. Prolonged dissociation with $800 \mathrm{U}$ protease resulted in more completely clean islets, but this was accompanied by substantial fragmentation.

\section{Effect of protease concentration on islet viability}

Pancreas dissociation was completed in 61 and $32 \mathrm{~min}$ when 100 and $800 \mathrm{U}$ protease were added, respectively. During dissociation with $100 \mathrm{U}$ protease the low proteolytic activity level in the medium increased only to a minimal extent and with $800 \mathrm{U}$ protease there was no increase in proteolytic activity (Table 1). This confirmed the effectiveness of BSA and trypsin inhibitors in eliminating the contribution of endogenous proteolytic enzymes.

Dissociation under our well-defined enzymatic conditions proceeds more slowly than that of routine islet isolations. This could be deleterious to islet function, even though warm ischaemia was avoided by shaking of the dissociation mixture in an oxygen-rich atmosphere. The isolated islets were, however, functional, as indicated by their insulin secretion in vitro (Table 1). Insulin secretion was slightly higher after isolation with $800 \mathrm{U}$ as compared to $100 \mathrm{U}$ protease but the stimulation factors (ratio of insulin secreted by ten islets at high and low glucose) were not dif- 
ferent $(7.9 \pm 0.6$ with $100 \mathrm{U}$ protease, $7.7 \pm 1.0$ with $800 \mathrm{U}$ protease).

\section{Discussion}

In this study the separate contributions of collagenase and protease to pancreas dissociation were analysed, independent of the effects of other enzymes originating from the commercial collagenase preparation or the pancreatic tissue itself. These conditions were met by adding various amounts of highly purified protease to purified collagenase and by elimination of the released endogenous proteolytic activity by adding BSA and trypsin inhibitors [3]. Thus, we were able to discriminate between the contributions of protease and collagenase to ECM hydrolysis, pancreas dissociation, islet integrity, islet function and islet yield. In this study, the pancreas was not inflated before chopping to ensure that a precisely defined amount of tissue was present in each incubation vessel but omitting inflation had no effect on the tissue dissociation and the islet yield (unpublished results).

Previously we have shown that islets can be isolated from rat pancreas by dissociating the tissue with purified collagenase for about $15 \mathrm{~min}[28,29]$. The extremely long dissociation time required in the present dissociations with purified collagenase (i.e. $99 \mathrm{~min}$ ) must be ascribed to the presence of BSA and trypsin inhibitors which eliminate all endogenous proteolytic activity during dissociation. The dissociation time was considerably reduced (i. e. to $36 \mathrm{~min}$ ) by the addition of $800 \mathrm{U}$ protease or more to collagenase, which illustrates that dissociation rates when using commercial collagenase are to a large extent determined by its protease activity. It would therefore be worthwhile to test defined mixtures prepared from purified collagenase and purified protease in the dissociation of pancreas from dog, pig and man.

The monitoring of the degradation of the major ECM components by histochemical methods proved to be a useful tool in the analysis of pancreas dissociation. As inferred from the sirius red staining, all collagen types [22] were effectively degraded by purified collagenase without protease. An unexpected observation was the disappearance of glycoproteins and proteoglycans from the ECM when pancreas was incubated with collagenase alone. The disappearance of these non-collagenous components was delayed as compared to that of the collagen, suggesting that it is a secondary effect of collagen degradation, i. e. diffusion of collagen degradation products from the tissue may result in the disappearance of other ECM components which are closely associated with collagen [15]. The disappearance of proteoglycans, which are extremely sensitive to proteolytic activity [31], in the absence of added protease may also be due to trace amounts of proteolytic enzymes from the tissue.

The acceleration of tissue dissociation by protease can be ascribed to degradation of protease-sensitive parts of proteoglycans and glycoproteins. The enhanced degradation of collagen can be explained from the breakdown of the collagen which escaped degradation due to coating with proteoglycans [32], but is hydrolysed following degradation of these ECM components by protease. In addi- tion, it cannot be excluded that protease, which is highly active against denatured collagen $[20,27]$, actually degrades collagen after partial degradation by collagenase.

The pancreatic islets obtained by dissociation of the tissue with purified collagenase in the absence of any proteolytic activity remained morphologically intact up to about $60 \mathrm{~min}$. In routine islet isolations with crude collagenase, without BSA and trypsin inhibitors, dissociation is completed in a shorter time period, usually about $15 \mathrm{~min}$. The fact that we observed no damage at all during the first $60 \mathrm{~min}$ of dissociation with purified collagenase alone must be ascribed to the presence of BSA and trypsin inhibitors since omitting these additions resulted in islet damage after only $15 \mathrm{~min}$ (data not shown). Addition of any amount of protease enhances the damage, the first signs being observed at a time ( $45 \mathrm{~min}$ ) when degradation of several ECM components is not yet complete.

High numbers of viable islets (3,289-3,789 islets/g pancreas), representing a total endocrine tissue volume of $4.2-5.0 \mu \mathrm{l} / \mathrm{g}$ pancreas, could be obtained under the present dissociation conditions. Not all islets were completely free of exocrine cells even though we found that $79-85 \%$ of the islet tissue could be recovered in the islet fraction after dextran density gradient centrifugation. Prolongation of the dissociation time caused islet fragmentation and a dramatic decrease of the total islet volume to less than $2 \mu 1 / \mathrm{g}$ pancreas, while the fraction of completely clean islets only slightly increased. Prolonged dissociation in the presence of protease induces preferential loss of the large islets since islet volumes were found to decrease more than islet numbers. Our observations indicate that the proteolytic activity present in collagenase preparations is essentially harmful to islets.

In our experience successful islet isolation requires the presence of high collagenolytic and low proteolytic activity [3]. McShane et al. [21] found that addition of dispase, a neutral protease produced by Bacillus polymyxa, to a collagenase batch with a low caseinase activity significantly improved islet yield. This favourable effect of dispase seems to contradict that $C$. histolyticum neutral protease is harmful to islets. However, a direct comparison of these two reports is hampered by the fact that (1) McShane et al. [21] used different conditions which resulted in much lower islet yields, (2) they did not eliminate the proteolytic activity released by the pancreatic tissue, and (3) commercial dispase is different from $C$. histolyticum protease (mol. wts. 40 and $35 \mathrm{kDa}$, respectively; data not shown).

Our results show that protease plays a dual role in islet isolation. On the one hand protease accelerates tissue dissociation by enhancing the degradation of the four major ECM components. On the other hand the enzyme accelerates the process of islet disintegration. This finding can be explained by the observation that islet integrity depends largely on protease-sensitive cell-cell adhesion mechanisms, not only in the rat but also in dog, pig and man [33]. Complete omission of all proteolytic activity would solve the problem of islet disintegration. However, our study shows that some proteolytic activity is required for adequate dissociation of pancreatic tissue. We conclude, therefore, that successful islet isolation requires both collagenolytic and proteolytic activity, but that the 
proteolytic activity should be limited in order to obtain high yields of viable islets. These findings are pertinent to the definition of the optimal composition of enzymatic preparations for islet isolation.

Acknowledgements. We thank Mr. A.Pasma and Dr. P.T.R.van Suylichem for the histochemical analyses, Ms. A.M. A. Weemaes and Ms. M.W.A. Vonk for determining islet yield and function, and Ms. C.Schotpoort-Ostermeier for preparing the manuscript. This work was supported by grants from the Diabetes Research Foundation of The Netherlands and the AZG Research Fund.

\section{References}

1. Burghen GA, Murrell LR (1989) Factors influencing isolation of islets of Langerhans. Diabetes 38 [Suppl 1]: 129-132

2. Sharp DW (1988) The elusive human islet: variables involved in its effective recovery. In: Van Schilfgaarde R, Hardy MA (eds) Transplantation of the endocrine pancreas in diabetes mellitus. Elsevier, Amsterdam, pp 97-107

3. Wolters GHJ, Van Suylichem PTR, Van Deijnen JHM, Van Schilfgaarde R (1990) Factors influencing the isolation process of islets of Langerhans. Horm Metab Res 25 [Suppl]:20-26

4. Alejandro R, Strasser S, Zucker PF, Mintz DH (1990) Isolation of pancreatic islets from dogs; semi-automated purification on albumin gradients. Transplantation 50:207-210

5. Ricordi C, Socci C, Davalli AM et al. (1990) Swine islet isolation and transplantation. Horm Metab Res 25 [Suppl]: 26-30

6. Warnock GL, Kneteman NM, Evans MG, Rajotte RV (1990) Isolation of purified large mammal and human islets of Langerhans. Horm Metab Res 25 [Suppl]: 37-44

7. Hering BJ, Bretzel RG, Federlin K (1988) Current status of clinical islet transplantation. Horm Metab Res 20:537-545

8. Scharp DW, Lacy PE, Santiago JV et al. (1991) Results of our first nine intraportal islet allografts in type I, insulin-dependent diabetic patients. Transplantation 51: 76-85

9. Warnock GL, Kneteman NM, Ryan EA, Rabinovitch A, Rajotte RV (1992) Long-term follow-up after transplantation of insulinproducing pancreatic islets into patients with type 1 (insulin-dependent) diabetes mellitus. Diabetologia 35: 89-95

10. Tzakis AG, Ricordi C, Alejandro R et al. (1990) Pancreatic islet transplantation after upper abdominal exenteration and liver replacement. Lancet 336: 402-405

11. London NJM, Lake SP, Wilson J et al. (1990) A simple method for the release of islets by controlled collagenase digestion of the human pancreas. Transplantation 49: 1109-1113

12. Overholser MD (1925) The number of islets of Langerhans in the pancreas of the albino rat. Endocrinology 9: 493-504

13. Hellman B (1959) The numerical distribution of the islets of Langerhans at different ages in the rat. Acta Endocrinol 32: 63-77

14. Van Suylichem PTR, Wolters GHJ, Van Schilfgaarde R (1992) Peri-insular presence of collagenase during islet isolation procedures. J Surg Res (in press)

15. Martinez-Hernandez A (1987) Electron immunohistochemistry of the extracellular matrix: an overview. In: Cunningham LW (ed), Methods in enzymology, Vol. 145, Structural and contractile proteins, Part E: Extracellular matrix. Academic Press, New York, pp 78-103

16. Bond MD, Van Wart HE (1984) Characterization of the individual collagenases from Clostridium histolyticum. Biochemistry 23: 3085-3091
17. Van Wart HE, Steinbrink DR (1985) Complementary substrate specificities of class I and class II collagenases from Clostridium histolyticum. Biochemistry 24: 6520-6526

18. Kessler E, Yaron A (1973) A novel aminopeptidase from Clostridium histolyticum. Biochem Biophys Res Commun 50: 405- 412

19. Mitchell WM, Harrington WF (1968) Purification and properties of clostridiopeptidase B (clostripain). J Biol Chem 243: 46834692

20. McQuade AB, Crewther WG (1968) Peptide substrates for a proteinase of Clostridium histolyticum. Biochim. Biophys Acta $167: 619-620$

21. McShane P, Sutton R, Gray DWR, Morris PJ (1989) Protease activity in pancreatic islet isolation by enzymatic digestion. Diabetes 38 [Suppl 1]: 126-128

22. López-de León A, Rojkind M (1985) A simple micromethod for collagen and total protein determination in formalin-fixed paraffin-embedded sections. J Histochem Cytochem 33: 737-743

23. Van Suylichem PTR, Pasma A, Wolters GHJ, Van Schilfgaarde R (1987) Microscopic aspects of the structure and collagen content of the pancreas from the perspective of islet isolation. Transplant Proc 19: 3958-3959

24. Romeis B (1989) Mikroskopische Technik, 17th edn. Urban und Schwarzenberg, Munich, Vienna, Baltimore, pp 441-624

25. Latif ZA, Noel J, Alejandro R (1988) A simple method of staining fresh and cultured islets. Transplantation 45: 827-830

26. Van Suylichem PTR, Wolters GHJ, Van Schilfgaarde R (1990) The efficacy of density gradients for islet purification: a comparison of seven density gradients. Transplant Int 3: 156-161

27. Hefley TJ (1987) Utilization of FPLC-purified bacterial collagenase for the isolation of cells from bone. J Bone Mineral Res 2: 505-516

28. Wolters GHJ, Konijnendijk W, Bouman PR (1977) Effects of fasting on insulin secretion, islet glucose metabolism and the cyclic adenosine 3', 5'-monophosphate content of rat pancreatic islets in vitro. Diabetes 26:530-537

29. Wolters GHJ, Konijnendijk W (1980) Relationship between insulin secretion, insulin content and dry weight of single rat pancreatic islets. Acta Endocrinologica 94: 365-370

30. Laemmli VK (1970) Cleavage of structural proteins during assembly of the head of bacteriophage T4. Nature 227: 680-685

31. Heinegard D, Sommarin Y (1987) Isolation and characterization of proteoglycans. In: Cunningham LW (ed) Methods in enzymology, Vol. 144, Structural and contractile proteins, Part D: extracellular matrix. Academic Press, New York, pp 319-372

32. Linares HA, Laros DL (1978) Proteoglycans and collagenase in hypertrophic scar formation. Plast Reconstr Surg 62: 589-593

33. Van Deijnen JHM, Hulstaert CE, Wolters GHJ, Van Schilfgaarde R (1992) Significance of the peri-insular extracellular matrix for islet isolation from the pancreas of rat, dog, pig and man. Cell Tissue Res 267: 139-146

Received: 30 January 1992

and in revised form: 24 April 1992

Dr. G.H.J.Wolters

Department of Surgery

University of Groningen

Bloemsingel 1

NL-9713 BZ Groningen

The Netherlands 